\title{
Northern State University Teacher Induction: Reflections And Assessments On First-Year Teaching Experiences
}

Craig D. Kono, Northern State University, USA

\begin{abstract}
The purpose of this paper is to report on the elementary and secondary school experiences of first year classroom teachers who participated in the Northern State University Teacher Induction Program during the 2007-2008 school year. Most of the participants were primarily employed as classroom teachers in large and small schools across South Dakota, with three first-year teachers located out of South Dakota. The NSU Teacher Induction Program is a follow-up support program for new teachers graduating from Northern State University and entering their first year of teaching. The Teacher Induction Program collects data reflecting the first-year experiences of new teachers, and documents trends and issues to be addressed by NSU faculty.
\end{abstract}

Keywords: Induction, first-year teacher, Northern State University, new teacher, assessment, performance

\section{INTRODUCTION}<smiles>[LiH]</smiles>

chools in the United States hire nearly 200,000 teachers each year. By the end of their first year 22,000 of those new teachers will leave education, at the end of their third year 33 percent of new teachers will leave, and 46 percent of new teachers will leave education after five years (Ingersoll, 2005). As stated by Allen in Renard (2000) "new teachers are not finished products." "Expecting them to perform like seasoned professionals is unrealistic". A study from North and South Carolina, indicated that positive teaching conditions are significant predictors of student achievement and teacher retention (Scherer, 2005). Hoerr (2005) states, "good administrators recognize that if we want our teachers to be successful, we need to consider the range of their needs". In South Dakota, 60 percent of teachers will retire in the next 25 years. South Dakota schools are already facing a serious teacher shortage, and the data reflects the need for South Dakota schools and universities to help keep new teachers in education (ASBSD, 2005).

This purpose of this study was to research the K-12 classroom experiences of first-year teachers and study the classroom and school factors that may affect their future chances of success in education. The subject of the research was first-year teachers, graduating in the spring semester 2007 from Northern State University in Aberdeen, South Dakota. Twenty-three first-year teachers participated in this survey, with most of them primarily employed in large and small public schools across rural South Dakota. At least three of the participants taught in other states such as Alaska, Arizona, and Colorado. School administrators from each of the first-year teacher's new schools were also asked to participate in this survey for the purpose of comparing their impressions of their first-year teachers with the self-assessment responses of the new teachers themselves.

School administrators and first-year teachers were asked to participate by assessing, and self-assessing, first year teaching experiences by using a scoring rubric developed from Charlotte Danielson's book Enhancing Professional Practice: A Framework for Teaching. Danielson's book was published by the Association for Supervision and Curriculum Development, and has been widely acclaimed as a strong resource for defining specific domains, elements, and components of the teaching task. 
Both first-year teachers and school administrators were asked to make their assessments based on a Lickert scale score from an "A" grade to F. An "A" represented the highest score possible and an "F" represented the lowest score possible. Ratings were based on Danielson's four domains of instruction including planning and preparation, classroom environment, classroom instruction, and professional responsibilities. The purpose of creating the scoring rubric was to collect data reflecting the school supervisor's performance assessment of the first-year teacher's experiences in education, and each first-year teacher's own self-assessment.

Twenty specific elements from four generic domains of teaching were used as a primary basis for assessing and self-assessing the first-year teacher's classroom performance:

\section{Planning \& Preparation}

- $\quad$ Content Knowledge

- $\quad$ Quality of Learning Activities Prepared

- $\quad$ Understanding Special Needs

- $\quad$ Quality of Organization

- $\quad$ Quality of School Resources

\section{Classroom Environment}

- Interactions with Students

- $\quad$ Classroom Transitions

- $\quad$ Managing Student Behavior

- $\quad$ Responses to Student Misbehavior

- Technology Resources

\section{Classroom Instruction}

- $\quad$ Setting Fair Expectations

- $\quad$ Clarity and Pacing of Instruction

- $\quad$ Quality of Learning Activities Used in Class

- Understanding the Learning Process

- Understanding Classroom Diversity

\section{Professional Responsibilities}

- Interactions with Other Teachers

- $\quad$ Managing Records

- $\quad$ Service to the School

- $\quad$ Professionalism

- $\quad$ Decision Making Skills

The survey was conducted in two separate phases during the fall semester and spring semesters of the 2007-2008 school year. Twenty-three first year teachers and school administrators participated in the first phase of the survey in the autumn of 2007 using the Charlotte Danielson scoring rubric. A second phase of the survey was also scheduled in the spring of 2008 using a smaller group of nine of the original twenty-three first-year teachers. The purpose of conducting a second, smaller in-depth oral interview phase was to gather more specific thoughts, reflections, and personal information about new teachers during their first full year of teaching. The second phase questions asked new teachers to reflect on school environmental issues, student and parent issues, and to assess their general impressions of education from their first-year in teaching. 


\section{DATA}

\section{Phase One: Comparing Performance Assessments Of School Principals And First-Year Teachers}

Planning and preparation is the first of four teaching domains that school principals and first-year teachers graded performance. For the most part school administrators graded NSU first-year teachers very favorably with a grade of "A" for elements of content knowledge and quality of planned learning activities. New teachers were graded very highly by their principals when assessing organizational skills. School administrators rated first-year teachers less favorably when it came to understanding the special needs of students. No teachers were given a failing grade for planning and preparation skills, but at least one student did receive a grade of " $\mathrm{D}$ " for their organizational skills.

Table 1: School Principal Assessment of First-year Teacher's Planning and Preparation Skills

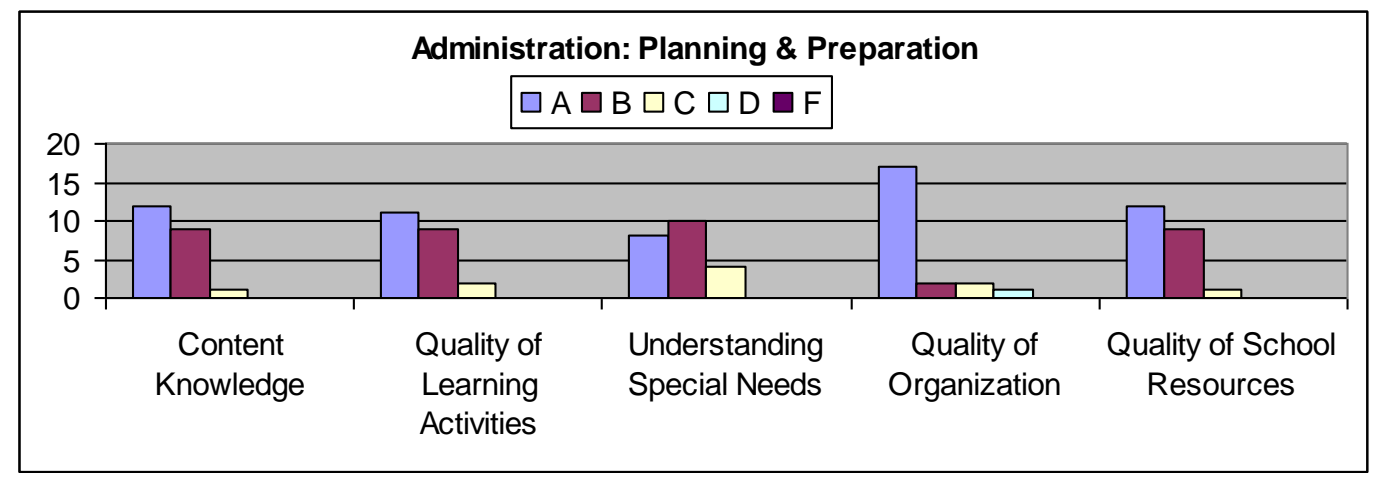

First-year teachers tended to score themselves more critically, and less favorably than did their school administrators for their skills in planning and preparation. First-year teachers typically gave themselves a grade of " $\mathrm{B}$ " in four of five elements within the domain of planning and preparation. NSU first-year teachers scored their own first-year teaching performance lower for such elements as content knowledge, quality of learning activities, and understanding the special needs of students. At least one first-year teacher gave themselves a grade of " $D$ " for understanding special needs of students, but no first-year teacher gave themselves a failing grade in any of the five elements of planning and preparation.

Table 2: First-year Teacher Self-Assessment of Planning and Preparation Skills

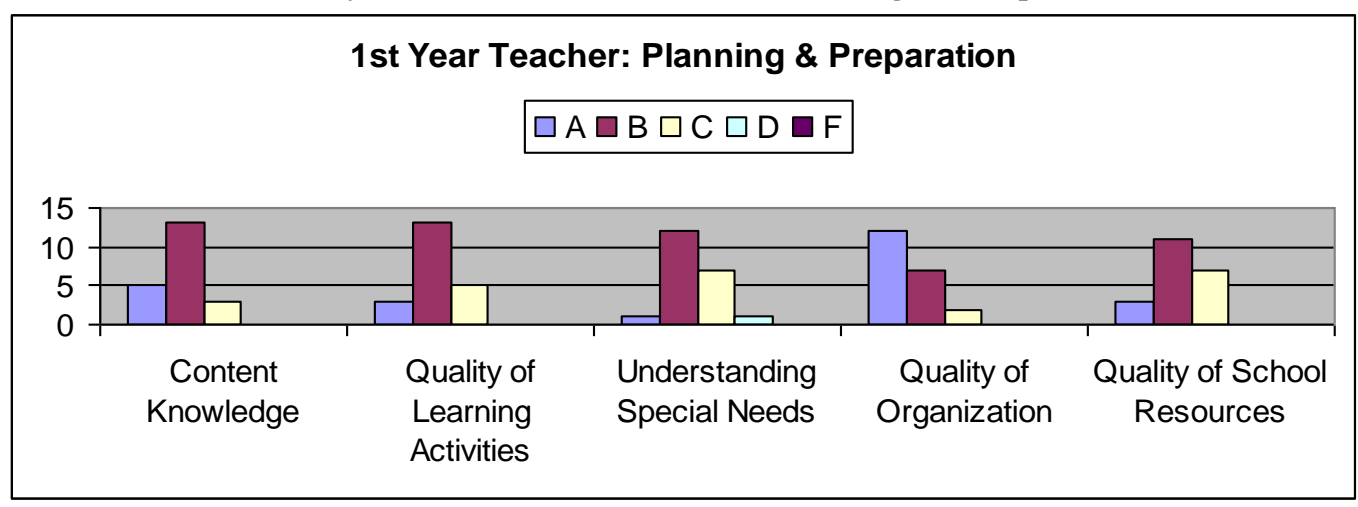


Classroom environment was the second of four teaching domains that principals and first-year teachers graded. While scores within the domain of classroom environment were still mostly positive, school administrators tended to rate first-year teachers less favorably in three of five environmental elements, such as interactions with students, managing student behavior, and responses to student misbehavior. While no first-year teacher was given a failing grade in any of the five classroom environment elements, they were given more grades of "B" and "C", and several grades of " $\mathrm{D}$ " for their interactions with students, management student behavior, and responses to student misbehavior.

Table 3: School Principal Assessment of First-year Teacher's Classroom Environment

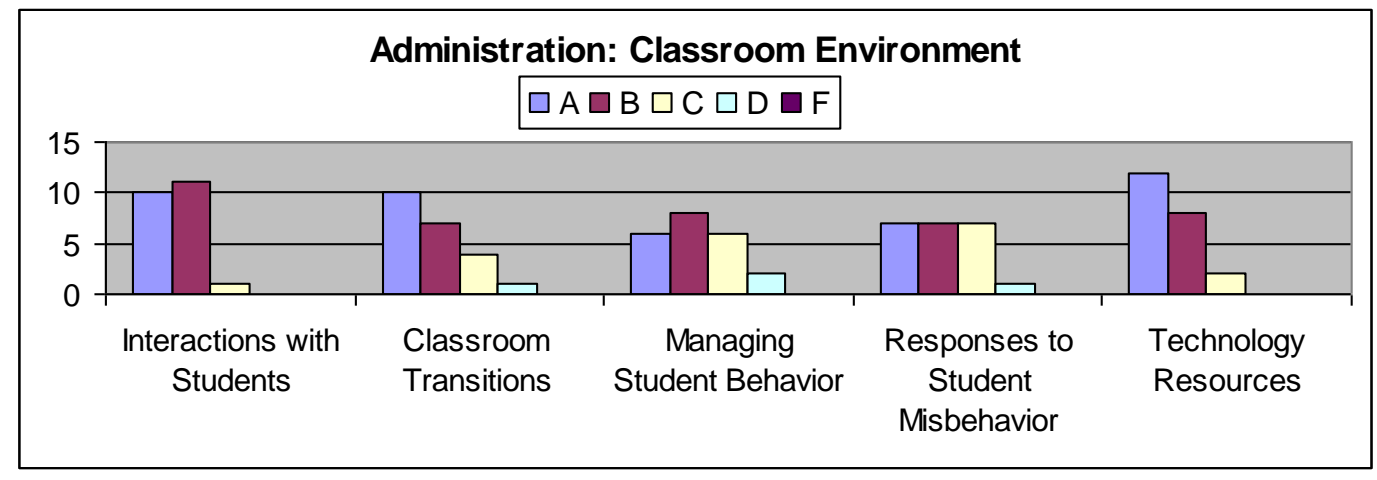

New NSU teachers gave themselves higher grades of "B" for two of five elements than did their supervisors for classroom environment issues. First-year teachers tended to grade themselves more favorably than did their school administrators when it came to classroom environment skills such as managing student behavior and responses to student misbehavior. However, first-year teachers did score their own performance considerably lower than their principals for their interactions with students, classroom transitions, and use of technology resources. A few first-year teachers issued grades of " $D$ " for their skills with responses to student misbehavior and use of technology resources.

Table 4: First-year Teacher's Self-Assessment of Classroom Environment

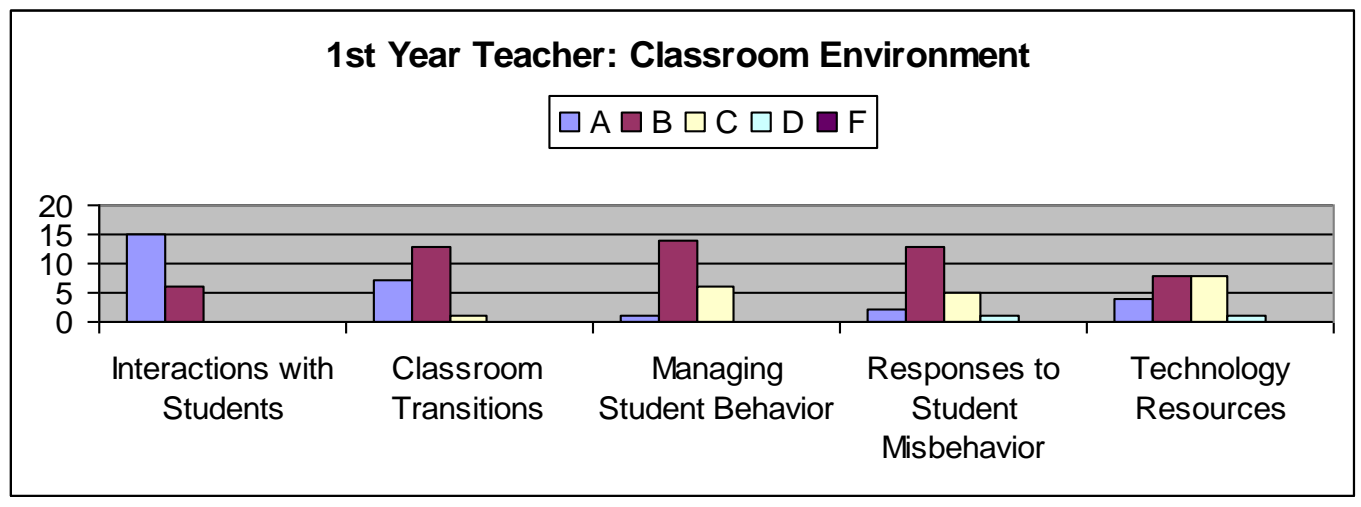

Classroom instruction was the third of four teaching domains that principals and first-year teachers graded. Principals generally gave NSU first-year teachers very favorable grades of "A" for each of the elements of classroom instruction. Top scores included demonstration of skills, such as setting fair expectations, clarity and pacing of instruction, quality of learning activities, understanding the learning process, and awareness of pupil 
diversity. At least a few grades of " $\mathrm{D}$ " were given to first-year teachers for clarity and pacing of instruction and the quality of learning activities used in the classrooms.

Table 5: School Principal Assessment of First-year Teacher's Classroom Instruction

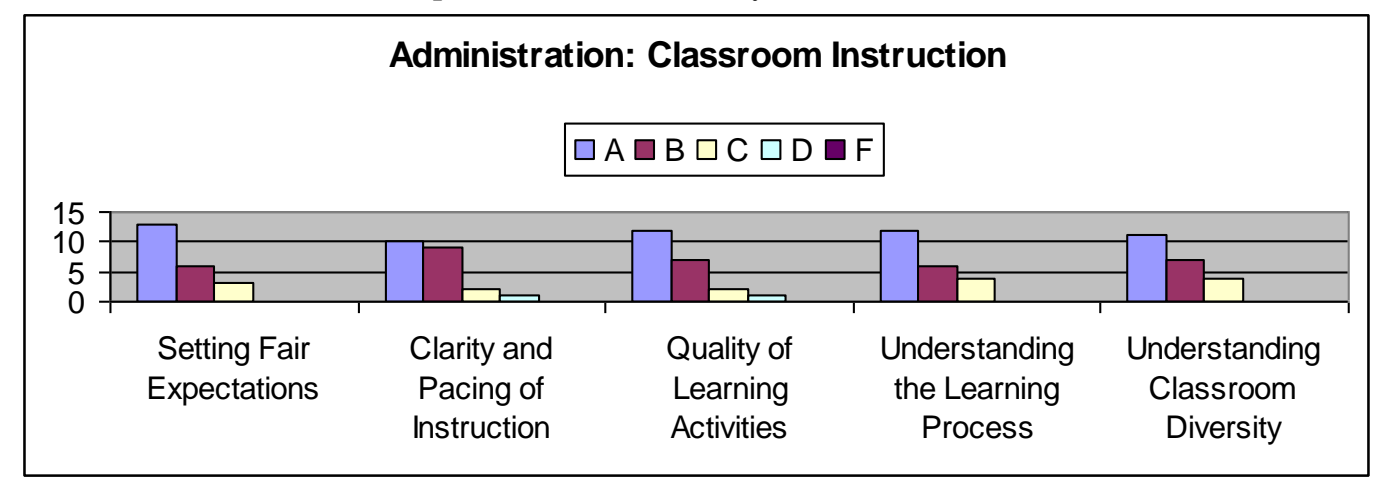

In four of the five elements of classroom instruction, first-year teachers tended to score their skills consistently lower than did their school administrators. First-year teachers gave themselves strong grades of "B" in four of the five classroom instruction elements compared to consistent grades of "A" given to them by their supervisors. Both school principals and first-year teachers issued grades of "A" for understanding student diversity, but at least one first-year teacher gave themselves a grade of " $\mathrm{D}$ " for understanding student diversity.

Table 6: First-year Teacher's Self-Assessment of Classroom Instruction

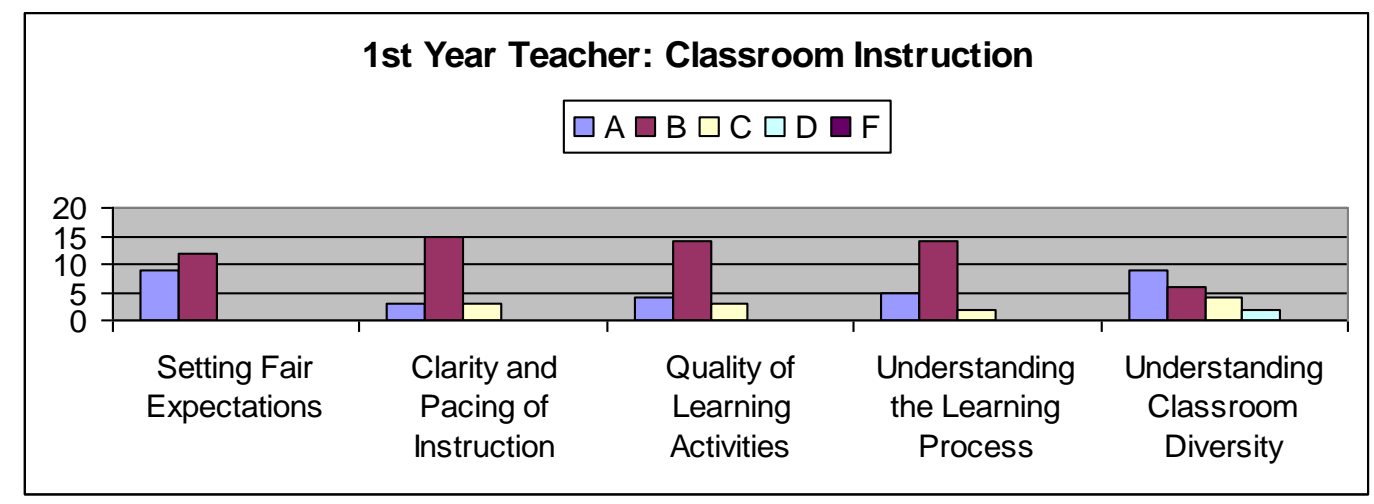

Professional responsibilities was the fourth and final teaching domain that principals and first-year teachers scored. Principals again gave their first-year teachers positive and consistent grades of " $\mathrm{A}$ " for their interactions with other teachers, management of school records, service to the school, professionalism, and decision making skills. School administrators gave no grades of " $\mathrm{D}$ " in any of the elements within the domain of professional responsibilities. 
Table 7: School Principal Assessment of First-year Teacher's Professional Responsibilities

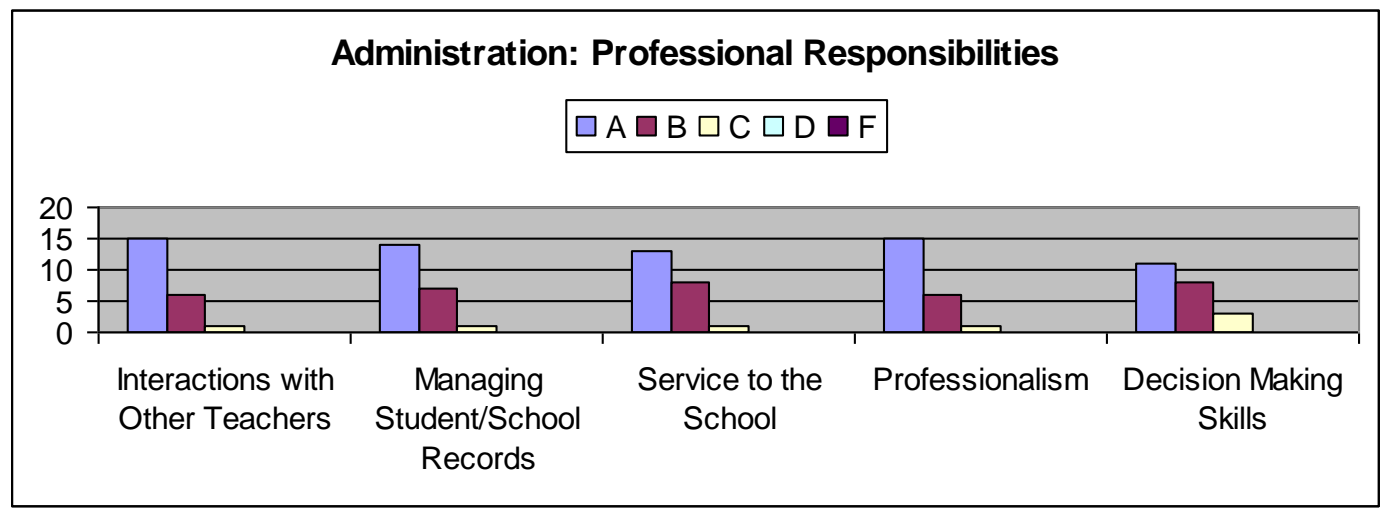

First-year teachers rated themselves favorably with grades of "A" in three of five elements of professional responsibilities such as interactions with other teachers, managing school records, and professionalism, but first-year teachers rated themselves less favorably with grades of "B" when offering service to the school and decision making skills. First-year teachers consistently gave themselves grades of " $A$ " and " $B$ " in each of the five elements of professional responsibilities, and only gave themselves " $\mathrm{C}$ 's" in two of five elements. Overall, school principals graded first-year teacher's professional responsibilities skills higher than did the first-year teachers with grades of "A" in each of the five elements.

Table 8: First-year Teacher's Self-Assessment of Professional Responsibilities

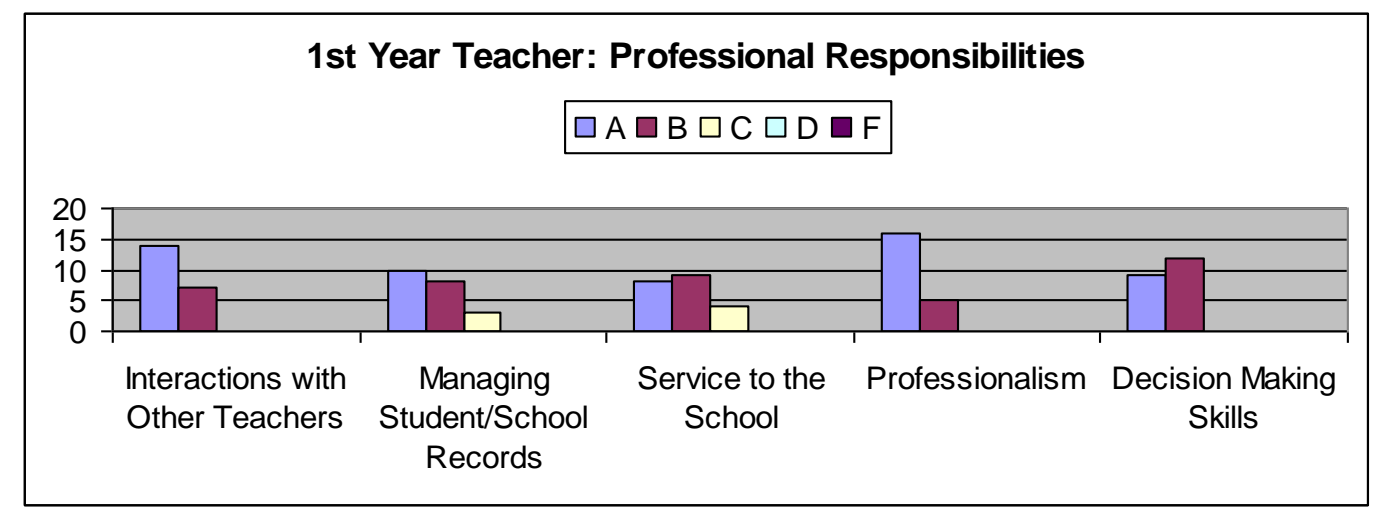

\section{Phase Two: Reflections On The First Year In The Classroom}

During the second phase of the research project, nine first-year teachers volunteered for an oral interview to be conducted at their school site. First-year teachers were asked a series of ten questions concerning specific environmental concerns during their initial first year in education. Questions ranged from the types of mentorship and induction programs that were made available to them, unusual circumstances that affected their teaching, interactions with parents and students, and how they believe they changed during their first year in teaching.

When asked if their school had an induction or mentorship program to help first-year teachers make adjustments in the teaching profession, five of the nine teachers said they were assigned a mentor or teaching partner that offered assistance to help them with school tasks. None of the schools had a structured, planned teacher induction program, and four of the nine schools had no mentorship program of any type, but new teachers did feel 
comfortable asking colleagues for help if needed. One new teacher was offered the opportunity to participate in a first-year teacher training program, but scheduling conflicts prevented her from attending. Each of the nine teachers explained how they had good relationships with fellow teachers and they had no difficulties asking for help if needed.

An essential part of the adjustment process for first years in education is building a quality working relationship with their school principal. Quite often the principal-teacher relationship can make or break a first year teacher in the classroom. When asked to describe their relationship with their principal, eight of the nine first-year teachers said they had a good relationship with their immediate school supervisor. These new teachers said their principal was helpful and willing to offer assistance or advice to the first-year teacher when needed. In fact, the majority of the descriptions offered about principal could be described as very positive. One potentially negative comment concerned the inconsistent availability of their principal when they had two separate schools sites to serve as administrator. Another first year teacher described her principal as "a nice guy," but that he was too "wishywashy" and not helpful when it came to managing discipline problems or responding to general questions about school policies. The first-year teacher did say their relationship with their vice-principal was much better.

First-year teachers are often confronted with unusual or unpredictable circumstances that affect their first year in education. When asked if they were faced with any unusual or challenging circumstances during their first year in teaching, two first-year teachers related serious and extreme issues they encountered. One first-year teacher mentioned that her father had passed away within a month of the school year starting, and another new teacher related how two former students from her school had committed suicide during the school year. One of the two suicide victims involved a high school student hanging himself on the football goalposts on school grounds only to be discovered by the building janitor early on a school morning. The first-year teacher said other staff members were notified of the tragedy at the start of the school day, and were asked to black out school windows to prevent students from witnessing the recovery of the student's body outside their classroom windows. Needless to say, events like these have a profound effect on new teachers, students, and veteran staff members alike.

Other circumstances faced by most first-year teachers were more common school adjustment issues such as building noise, large class sizes, shortages of staff members, lack of technology resources, old school structures, lack of parental support, and the need to commute long distances to work each day. Two new teachers were also faced with the possibility of having their schools close due to reorganization and consolidation problems facing many smaller school districts in South Dakota.

One first-year teacher was employed in northern Alaska in a small fishing village on the Bering Sea. The stories of her first year experiences would be considered quite unusual for most teachers employed by rural school districts in South Dakota. The teacher's reflections concerned many social problems such as severe alcoholism and poverty that affect minority students in many remote Alaskan towns. She related how most of her school's students had grown up within the small community and had never been anywhere outside of their village. Since they had grown up in the baron Alaskan bush country, with no roads leaving or entering town, some children had never seen a tree, or even a simple highway stop sign. The town in which she taught was a subsistence community that ate whatever they killed and cooked whatever plants and berries they picked. Meals would often consist of food gathered in the wild or at sea, such as whale blubber. She did mention how the native custom of sharing food with more elderly members of the small town tended to bring people together and create a more close-knit community. She spoke very fondly of many of the children she taught in her classroom, and how she helped them learn throughout the school year.

First-year teachers were asked to reflect on adjustments they made in their classrooms from the first semester to the second semester. Almost all first-year teachers realized they needed to change their classroom organizational structure or their classroom discipline policies. One first-year teacher admitted she was constantly reflecting on her teaching style and making adjustments throughout the school year. Other new teachers said they pushed students harder, became more strict with classroom rules and behavior issues, changed methods of classroom presentations, and worked to improve their general management of their classroom in the second semester. It appeared as though classroom discipline and management issues from the first semester were the most significant 
factors that caused most of the first-year teachers to adjust and modify their approach to teaching. Other first-year teachers said they probably had to learn to relax a little more and become more familiar with school procedures.

Statistics show than almost half of America's new teachers will leave the teaching profession within the first five years. Most first-year teachers in the Northern State University Teacher Induction program strongly doubted they would leave education in the next five years. However, several first-year teachers stated if they were to leave education, the reason most often cited would be the role parents and community in small towns play in teaching and education.

Lack of parental support and poor community attitudes toward supporting public education in smaller, rural schools appeared to be a potentially significant source of frustration. One first-year teacher in a small farming community explained how parents seemed to enable, influence, and reinforce their children's negative attitudes toward education. Instead of positively influencing their child's increased education aspirations and attainment, parents simply envisioned their children graduating high school with basic skills, then entering the farming profession and starting family life. Two teachers from rural schools said they would probably stay in education, but it would have to be at a different school where local support for education was stronger and where a culture of low academic expectations was less evident. If they did not move to a different community with stronger support for education, they could possibly be driven from the education profession. Results from the interviews with nine firstyear teachers would make it difficult to describe parent-teacher relationships as being completely positive; a more accurate description of first-year teacher's initial experiences with parents would be mixed. Some parent-teacher relationships were described as good or okay, but several other first-year teachers described their relationships with parents as an area of stress and concern.

Several first-year teachers said the lack of communication opportunities was a barrier to improving their relationships with parents. Electronic mail is becoming more widely used as a communication tool between teachers and parents, but one potential issue with electronic mail communication was mentioned by a first-year teacher. She said that while e-mails are instant sources of communication, it is often difficult to sense the intent or tone of some messages. Misunderstandings from e-mails could possibly impede rather than help build positive relationships between parents and teachers. Most public schools in South Dakota are working to increase parent-teacher communication through internet websites such as the Dakota Digital Network and DDN campus. The digital network allows all teachers to routinely post student grades and parent messages through a secure internet website, and also allows parents immediate access to their child's report card.

Along with parental issues, student discipline is often mentioned as a source of frustration for first-year teachers. Surprisingly though, most of the first-year teachers in South Dakota schools said student discipline was just "part of the game", and described their discipline problems as more commonplace. They said they knew about issues with student misbehavior before they entered the education profession, and that it would probably not cause them to leave education. That being said, one first year teacher did admit that student discipline could ultimately cause her to seek a job outside of teaching. Her experiences with student misbehavior were more profound, stating that she has been the subject of profane comments from students at least every day of the school year. Another firstyear teacher did admit that disrespectful students could be the one factor that could cause them to leave education more than parents.

It has been documented that South Dakota has the lowest teacher salaries in the United States. Low teacher pay in South Dakota is a strong contributing factor to an increasing teacher shortage problem throughout the state. However, most first-year teachers entering the teaching profession in South Dakota from Northern State University did not consider low salaries as a severe impediment to entering education, or staying in education in South Dakota. Most of the first-year teachers knew teacher salaries were low when they first decided to enter the education profession. One first-year teacher from outside South Dakota did say that low pay was one factor that could prevent her from returning to the state. Another first-year teacher lamented how he had spent many, many hours working on his classroom curriculum, and commented how any other profession would have offered better compensation. 
The completion of the first year of teaching will often lend a sense of realization to new teachers, and cause them to reflect on the many teaching strategies and education processes they implemented during their first year in education. What kind of changes and adjustments would first-year teachers make when they returned to start their second year in the classroom ? When asked what lessons they had learned in their first-year in teaching, several new teachers mentioned how reflection played a large part of making adjustments throughout the school year. One new teacher said their expectation of teaching was very different than what they met in their first year of teaching, especially the importance of meeting state and federal standards imposed by national legislation. Another new teacher said they had now begun to understand how much work went into planning and preparing for each school day. Many of the first-year teachers could see more big changes coming in their second year of teaching, mostly related to discipline, implementing behavioral plans, more group participation activities, organization, and planning issues in the classroom.

When asked what were some of the greatest successes and challenges in their first-year of teaching most first-year teachers said just making it through the year was a success. They pointed toward how important it was to them to be seen as teachers in the education profession, and that it was nice to hear positive, supportive comments from their students. In particular, many first-year teachers mentioned how good it was to see their students improve during the school year, and how they felt they had changed some of their student's lives. One first-year teacher said the most successful experience of her school year was helping a kindergarten student go from not knowing any names or sounds of letters to actually being able to read, and another new teacher summed up her first year up this way, "I feel that I have actually taught them something!"

\section{CONCLUSIONS}

School principals appeared to be quite satisfied with the performance of new teachers they have employed from Northern State University. On average, school administrators tended to give very favorable grades to first-year teachers in their school districts. If principals had an area of concern, it would be with classroom management and student discipline issues. First-year teachers tended to be more critical of their own performance with many of their own self-assessments being graded lower than their supervisor's scores.

First-year teachers from Northern State University tended to have many of the typical adjustment problems common to new teachers just entering the education profession. First-year teachers struggled with student discipline issues, but they made efforts to change and improve during their second semester of teaching. Two first-year teachers had to manage tragic situations that occurred during their initial year in education. Parent relationships and expectations appeared to be of some concern to a number of first-year teachers, especially attitudes of parents concerning academic expectations and behavioral issues in smaller schools. First-year teachers described some parents as being enablers of their children's school difficulties rather than problem solvers. Most new teachers had successful experiences in their first year in education, and doubted that factors such as wages and salaries would affect their education careers. First-year teachers expressed pride in their efforts to teach children and expressed how they believed they had a positive effect on their lives. If first-year teachers continue to grow and change during their early years, it would appear they have established strong building blocks for continued success in education.

\section{AUTRHOR INFORMATION}

Craig D. Kono has served as classroom teacher, high school principal, and school superintendent in rural K-12 South Dakota schools from 1979 to 2001. He received his Bachelor's Degree in secondary education 1979 and his Masters Degree in Secondary Administration in 1988 from Northern State University in Aberdeen, South Dakota. He earned his Specialist Degree in school district administration in 1998, and his Doctor's Degree in Educational Administration from the University of South Dakota in 2001. Currently he is an Associate Professor of Educational Administration at Northern State University in Aberdeen, South Dakota preparing graduate students for careers in elementary and secondary administration. He also serves as coordinator and supervisor for the Northern State University Teacher Induction program which provides assistance to first-year teachers in education. 


\section{REFERENCES}

1. Allen, M. (2000). New Imperatives for Teacher Preparation. Teacher Preparation and Induction, 2(3).

2. Danielson, Charlotte (2007). Enhancing Professional Practice: A Framework for Teaching. VA: ASCD.

3. Monthly Bulletin: Teacher Retirement. Pierre, SD: Associated School Boards of South Dakota, 2006

4. Hoerr, Thomas (2005). Meeting New Teachers Personal Needs. Educational Leadership 62(8) 82-84

5. $\quad$ Ingersoll, Richard. (2005). School's Out. Edutopia, 1(3), 38-44

6. Renard, Lisa (2003). Setting New Teachers Up for Failure... Or Success. Educational Leadership 60(8) 62

7. Scherer, Marge (2005). The Right New Teachers. Educational Leadership 62(8) 7-7

\section{NOTES}

